\section{Pancreatic metastasis from osteosarcoma diagnosed by endoscopic ultrasound fine-needle aspiration biopsy (EUS-FNAB)}
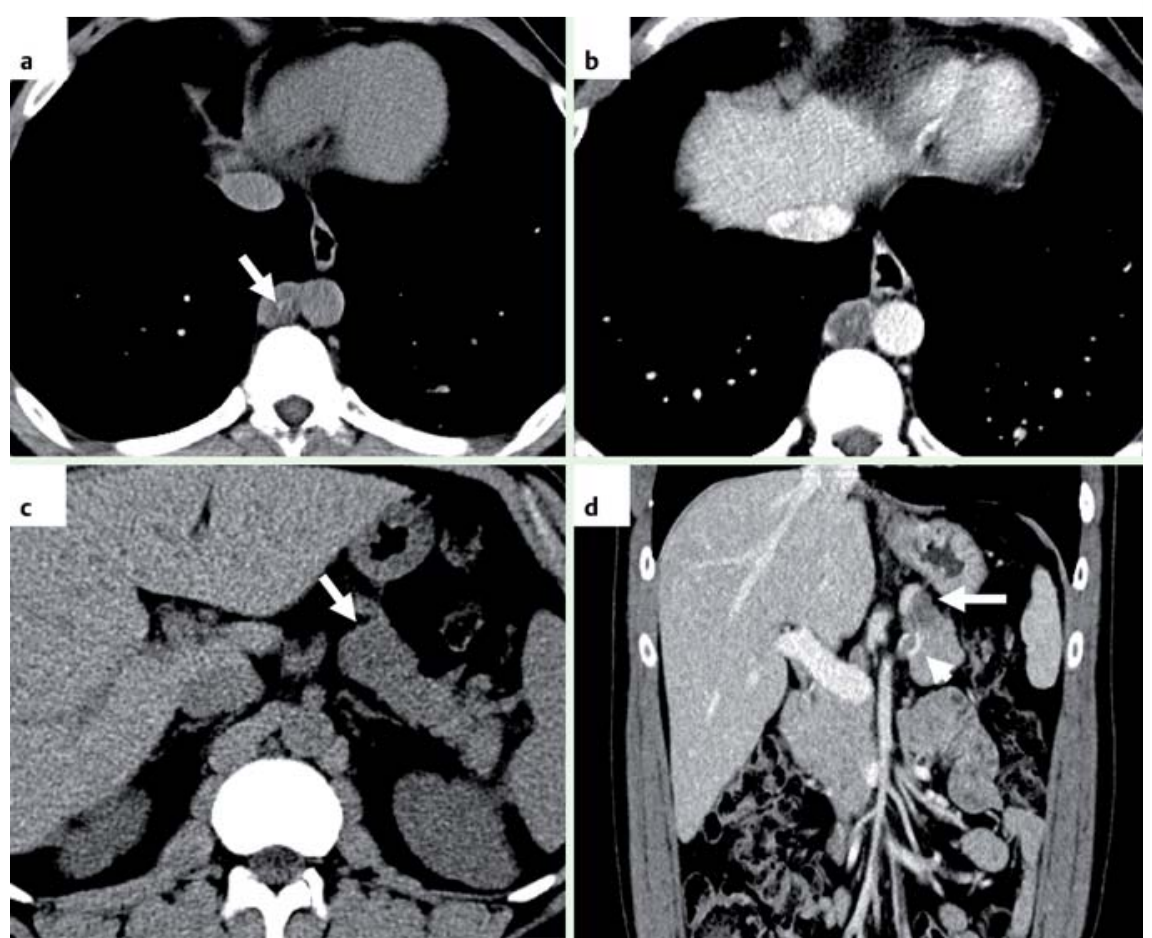

Fig. 1 Computed tomography (CT) scan of a 30-year-old man with history of high-grade chondroblastic osteosarcoma of the right maxillary sinus and recurrent lung metastases, showing the pancreatic and mediastinal metastases as hypodense masses with poor contrast enhancement after injection. a, b The latero-aortic posterior adenopathy was a $21-\mathrm{mm}$ mass, with a thin

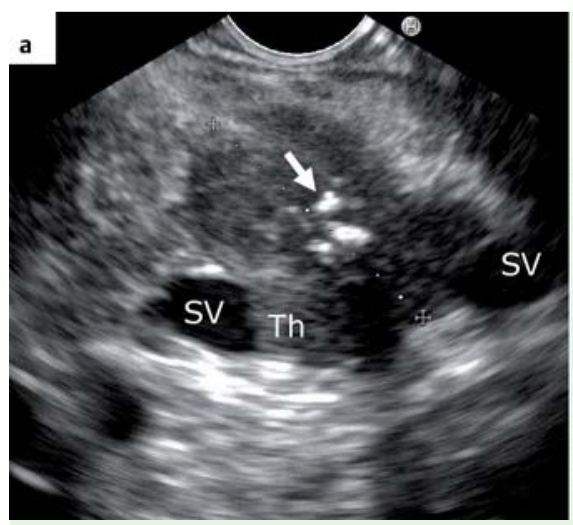

Fig. 2 a Endoscopic ultrasound (EUS) showing a 25-mm, well-limited, solid and hypoechoic mass of the pancreatic body-tail junction with thin central calcifications (arrow) and causing thrombosis (Th) of the splenic vein (SV). The aspect of
In 2008, a 30-year-old man with highgrade chondroblastic osteosarcoma of the right maxillary sinus was treated with a combination of polychemotherapy, surgery, and radiation therapy. In 2010, two lung metastases, detected on a computed tomography (CT) scan, were treated with percutaneous radiofrequency ablation. In 2011, an additional lung nodule was treated with radiofrequency ablation. After 6 months, in September 2011, a CT scan ( Fig. 1) revealed two suspect masses, a mediastinal adenopathy and a pancreatic tumor associated with a floating thrombus in the splenic vein. Endoscopic ultrasound (EUS) showed a pancreatic tumor with thin central calcifications, causing thrombosis of the splenic vein ( $\bullet$ Fig. 2 a). The lesion showed little enhancement after an injection of sulfur hexafluoride (SonoVue, Bracco International BV, Amsterdam, the Netherlands), and very high-density (strain ratio 105) on elastography, suggestive of malignancy. In the paracardial region, EUS revealed the adenopathy mass with a similar appearance as the pancreatic mass, with central calcifications. The two lesions were strongly suggestive of metastatic osteosarcoma. Fine-needle aspiration biopsy (FNAB) of both lesions was carried out ( $\bullet$ Fig. 2 b). The quality of the biopsy core samples was excellent, and histological analysis revealed two different areas of differentiation, including a poorly differentiated tumorous area consisting of small-sized round to fusiform cells and focal area of osteoid deposited in a fine lace-like pattern ( Fig.3). For both lesions, the diagnosis of metastasis from high-grade chondroblastic osteosarcoma was confirmed by the French Sarcoma Pathologist Network. After 3 cycles of ifosfamide/etoposide-based chemotherapy, the two lesions appeared stable on CT scan, and the patient was asymptomatic. He remains on chemotherapy 5 months after the diagnosis was made.

Osteosarcoma is an osteoid-producing tumor with high metastatic potential, but pancreatic secondary lesions are exceptional $[1,2]$. As exemplified by our case, EUS-FNAB [3-5] is a reliable method for diagnosis of pancreatic metastasis. Such an approach should be considered before any therapeutic decision is made, notably pancreatectomy, in patients with pancreatic mass and history of primary tumor. Use of EUS-FNAB should aid early detection of pancreatic metastases, when they are still amenable to potentially curative surgical removal. 


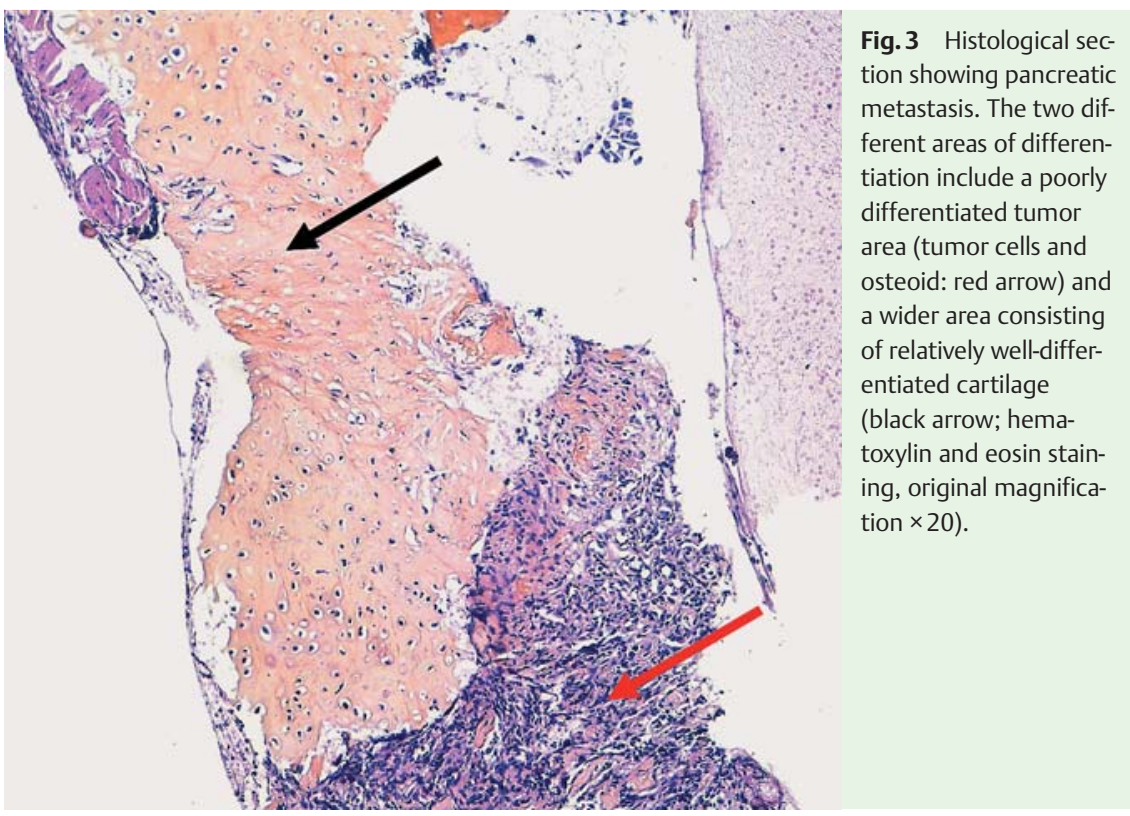

Endoscopy_UCTN_Code_CCL_1AF_2AZ_3AB

\section{Competing interests: None}

\section{F. Bertucci ${ }^{1,2}$, J. Araujo ${ }^{6}$, A. Sarran ${ }^{4}$, G. Monges ${ }^{5}$, J. A. Carvalho Junior ${ }^{6}$, D. Perrot ${ }^{1}$, E. Bories ${ }^{3}$, L. G. Rossini ${ }^{6}$, M. Giovannini ${ }^{3}$}

${ }^{1}$ Department of Medical Oncology, Institut Paoli-Calmettes, Marseille, France

${ }^{2}$ Aix-Marseille University, Marseille, France

${ }^{3}$ Department of Digestive Endoscopy, Institut Paoli-Calmettes, Marseille, France

${ }^{4}$ Department of Radiology, Institut PaoliCalmettes, Marseille, France

${ }^{5}$ Department of Pathology, Institut PaoliCalmettes, Marseille, France

${ }^{6}$ French-Brazilian Center of Endoscopic Ultrasound, Santa Casa de São Paulo University Hospital, São Paulo, Brazil

\section{Acknowledgments}

This work was supported by Institut PaoliCalmettes and Aix-Marseille University.

\section{References}

1 Adsay NV, Andea A, Basturk $O$ et al. Secondary tumors of the pancreas: an analysis of a surgical and autopsy database and review of the literature. Virchows Arch 2004; 444: 527-535

2 Lasithiotakis K, Petrakis I, Georgiadis G et al. Pancreatic resection for metastasis to the pancreas from colon and lung cancer, and osteosarcoma. JOP 2010; 11: 593-596

3 DeWitt J, Jowell P, Leblanc J et al. EUS-guided FNA of pancreatic metastases: a multicenter experience. Gastrointest Endosc 2005; 61: 689-696

4 Fritscher-Ravens A, Sriram PV, Krause C et al. Detection of pancreatic metastases by EUSguided fine-needle aspiration. Gastrointest Endosc 2001; 53: 65-70

5 Saftoiu A, Vilmann P, Gorunescu F et al. Accuracy of endoscopic ultrasound elastography used for differential diagnosis of focal pancreatic masses: a multicenter study. Endoscopy $2011 ; 43: 596-603$
Bibliography

DOI http://dx.doi.org/

10.1055/s-0031-1291643

Endoscopy 2012; 44: E151-E152

(c) Georg Thieme Verlag KG

Stuttgart · New York

ISSN 0013-726X

Corresponding author

\section{Dr M. Giovannini}

Institut Paoli-Calmettes

Department of Digestive Endoscopy

232, bd Sainte-Marguerite

13273 Marseille Cedex 09

France

Fax: +33-4-91-223658

giovanninim@marseille.fnclcc.fr

Araújo J et al. Pancreatic and lymph node metastases from maxillary osteosarcoma diagnosed by endoscopic ultrasound-guided fine needle aspiration. Endoscopy 2012; 44: E151-E152

This article has been corrected and updated and is replaced by a new version from Bertucci F et al. Pancreatic metastasis from osteosarcoma diagnosed by endoscopic ultrasound fine-needle aspiration biopsy (EUS-FNAB). The text has undergone minor editing and the authors list was augmented. 